\title{
A Classical Polarizable Force Field for Clays: Pyrophyllite and Talc
}

\author{
Stéphane Tesson, Mathieu Salanne, Benjamin Rotenberg, Sami Tazi, and \\ Virginie Marry* \\ Sorbonne Universités, UPMC Univ Paris 06, CNRS, Laboratoire PHENIX, Case 51, 4 \\ Place Jussieu, F-75005 Paris, France \\ E-mail: virginie.marry@upmc.fr \\ Phone: +33 (0)1 44272203
}




\begin{abstract}
We develop a classical polarizable force field for clays, based on the Polarizable Ion Model (PIM), focusing on two neutral clays: pyrophyllite and talc. The full set of parameters of the force field is determined from density functional theory calculations, using maximally localized Wannier functions with a force- and dipole-optimization procedure. Simulation results for our new polarizable force field (PIM) are compared to the state-of-the-art non-polarizable flexible force field (ClayFF), in order to assess the importance of taking polarization effects into account for the prediction of structural properties. This new force field is validated by comparing the detailed structure of the two minerals against X-ray data. Introducing polarization allows for a good transferability and better agreement with the experimental data, in particular for the subtle orientational deformation of the layers.
\end{abstract}




\section{Introduction}

Clay minerals, ${ }^{1-3}$ more precisely phyllosilicates, are minerals that constitute most of the soils and the sedimentary rocks. The wide use of clay minerals in industrial applications (catalytic activities: sorbents, filters, waste deposits), energy and ecological engineering (oil recovery, ground water remediation, geological barrier for radioactive waste and $\mathrm{CO}_{2}$ ) is partly due to their remarkable properties of retention at the mineral surface. The physico-chemical properties of clay minerals and their interfaces with fluid confined within their pores has been investigated since decades from both the experimental and theoretical points of view. Classical molecular simulations provide a detailed understanding on the microscopic scale, however their predictions rely on the model used to describe the interactions between the atoms. Therefore, several classical force fields have been developed. ${ }^{4-7}$ This allowed the use of molecular simulation to describe specific effects, including the prediction of the structure ${ }^{8-11}$ thermodynamics and dynamics of clays, ${ }^{10-13}$ their hydrophilic/hydrophobic properties ${ }^{14}$ or the sorption of ions. ${ }^{15-17}$

The veracity of results from molecular dynamics simulation strongly depends on the functional form and associated parameters of the force field used to calculate the interactions between atoms. The simulation must correctly describe the balance of interactions between the mineral and the interfacial fluid, reproduce the experimental structure, and capture the effects of ionic sizes and of the polarization of water molecules by ions. The reliability of the force field is even more important for the study of ionic solutions with multivalent ions or at the interface between clays and water molecules, because of multi-body effects. ${ }^{14,18-20}$ The force fields available in the literature for clays and their interfaces do not take into account the polarizability of molecules, ${ }^{4,5,7,21}$ even though it is known that polarization effects can play a significant role, especially in the presence of an electric field at the interface. ${ }^{22}$ Since the numerical results do not always reproduce quantitatively the experimental data, the relevance of the interpretation of microscopic simulations may be questioned. ${ }^{23}$

In the case of pure oxide materials, Madden et al. have developed a series of Polarizable 
Ion Models (PIM) and Aspherical Ion Models (AIM) from ab initio simulations. ${ }^{24-27}$ In particular, Jahn et al. ${ }^{28}$ have determined a full set of AIM parameters for the Ca-Mg-Al-Si-O (CMAS) system, which is the main component of the Earth's crust and mantle. However, this force field cannot readily be extended to aqueous solutions. We have recently shown that polarization effects play an important role in the physico-chemical properties of ions dissolved in water. ${ }^{29-31}$

In the present work, we extend the PIM model to clay minerals. Following the strategy of Madden et al., we derive the parameters of a force field for pyrophyllite and talc. Contrary to the parametrization of many force fields, the use of Density Functional Theory (DFT) calculations, using Maximally Localized Wannier Functions (MLWFs) ${ }^{32}$ with a forceand dipole-optimization procedure, ${ }^{18}$ renders experimental input unnecessary. Clays are layered aluminosilicates, with a large lateral extension compared to their width $(\sim 1 \mathrm{~nm})$. We focus here on two specific uncharged clays of the smectite family, namely pyrophyllite ${ }^{33}$ and talc. ${ }^{34}$ The manuscript is organized as follows. After introducing the microscopic structures of pyrophyllite and talc, we describe in detail the polarizable force field and its parametrization. Then, the force field is validated by a comprehensive comparison of its prediction of the structure with experimental data.

\section{Structure of pyrophyllite and talc}

Pyrophyllite and talc are two neutral phyllosilicate clays. They are composed of layers piled on top of each other to form particles. Each layer consists of two tetrahedral sheets sandwiching an octahedral sheet (TOT structure). Tetrahedral sheets is composed of basal oxygen $\left(\mathrm{O}_{\mathrm{b}}\right)$, apical oxygen $\left(\mathrm{O}_{\mathrm{a}}\right)$ and silicium $(\mathrm{Si})$ atoms, while the octahedral sheet contains apical oxygen atoms, hydroxyl groups $(\mathrm{OH})$ and aluminum or magnesium cations. These sheets are thus made from two cristallographic units: $\mathrm{SiO}_{4}$ tetrahedra and $\mathrm{XO}_{4}(\mathrm{OH})_{2}$ octahedra (where $\mathrm{X}$ is a cation, in our case $\mathrm{M}=\mathrm{Al}$ or $\mathrm{Mg}$ ), represented in Figure 1. 
Tetrahedra within a given sheet are linked by basal oxygen atoms $\left(\mathrm{O}_{\mathrm{b}}\right)$. The connection between base structures forms a hexagonal basal plane (Figure 2(a)). The tetrahedral and octahedral sheets are connected by the apical oxygen $\left(\mathrm{O}_{a}\right)$. Within the octahedral sheet, each octahedron shares two hydroxyl oxygens $\left(\mathrm{O}_{\mathrm{OH}}\right.$ and $\left.\mathrm{O}_{\mathrm{OH}}^{\mathrm{b}}\right)$ and four apical oxygens: $\mathrm{O}_{\mathrm{a}}(1), \mathrm{O}_{\mathrm{a}}(1)^{\mathrm{b}}, \mathrm{O}_{\mathrm{a}}(2)$ and $\mathrm{O}_{\mathrm{a}}(2)^{\mathrm{b}}$ (the exponent $\mathrm{b}$ indicates oxygen or hydroxyls on the same side of the octahedral sheet). An octahedral site can be occupied by a six-fold coordinated cation. In a tri-octahedral clay such as talc, all octahedral sites are occupied by a divalent ion $\left(\mathrm{Mg}^{2+}\right.$ in talc), whereas in di-octahedral clays such as pyrophyllite, two thirds of these sites are occupied by trivalent ions $\left(\mathrm{Al}^{3+}\right.$ in pyrophyllite), as illustrated in Figures 2(b) and 2(c). The elementary cell of pyrophyllite is therefore $\mathrm{Si}_{8} \mathrm{Al}_{4} \mathrm{O}_{20}(\mathrm{OH})_{4}$ and that of talc is $\mathrm{Si}_{8} \mathrm{Mg}_{6} \mathrm{O}_{20}(\mathrm{OH})_{4}$. Top and side views of pyrophyllite and talc layers are given in Figure 3.

Figure 1: Nomenclature of the atoms of the tetrahedral (left) and the octahedral (right) sites. 


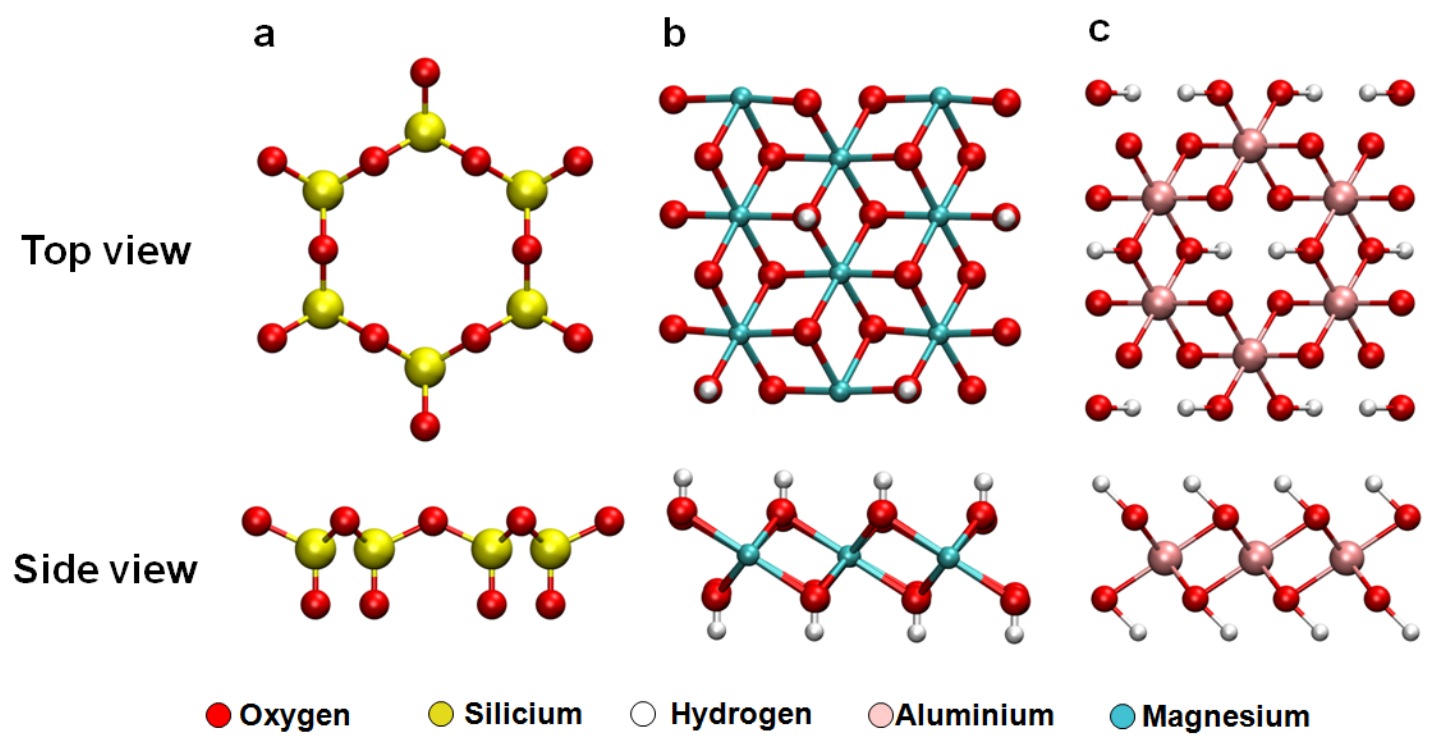

Figure 2: Side and top view of (a) tetrahedral, (b) trioactahedral and (c) dioctahedral sheet.

\section{The Polarizable Force Field}

The PIM force field is composed of four different terms: charge-charge, dispersion, overlap repulsion and polarization:

$$
V_{\text {total }}=V_{\text {Charge }}+V_{\text {Dispersion }}+V_{\text {Repulsion }}+V_{\text {Polarization }}
$$

The first term corresponds to the electrostatic interaction between two charges,

$$
V_{\text {Charge }}=\sum_{i<j}\left(\frac{q^{i} q^{j}}{r_{i j}}\right)
$$

where $q^{i}$ and $q^{j}$ are the charges of each atom and $r_{i j}$ is the distance between them. Here the formal charges are used, they are: $\mathrm{O}^{2-}, \mathrm{OH}^{-}, \mathrm{Mg}^{2+}, \mathrm{Al}^{3+}$ and $\mathrm{Si}^{4+}$. Charge transfer within the hydroxyl group, of total charge -1 , is modelled by partial charges on the corresponding atoms: $\mathrm{O}_{\mathrm{OH}}^{(2-\delta)-}$ and $\mathrm{O}_{\mathrm{H}}^{(1-\delta)+}$.

The second term in Eq. 1 corresponds to the dispersion interaction, due to the instantaneous 
Side view

a

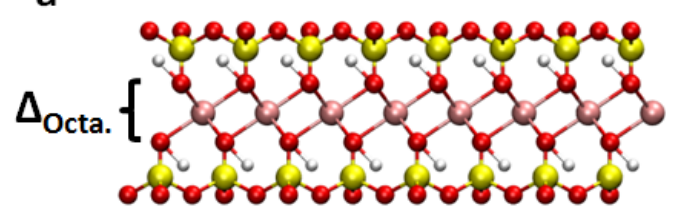

b

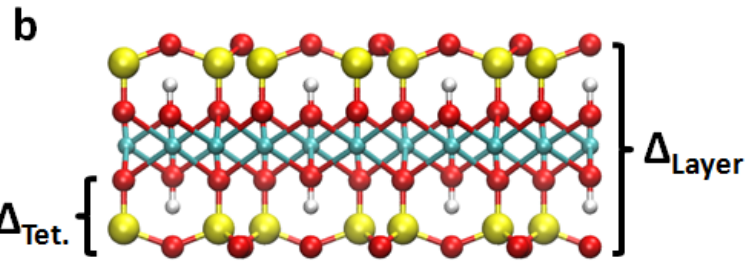

Top view
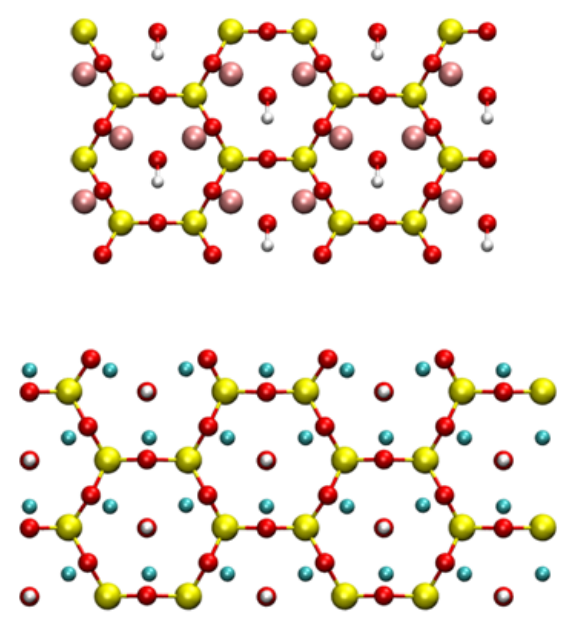

- Oxygen $\bigcirc$ Silicium $\bigcirc$ Hydrogen $\bigcirc$ Magnesium $\bigcirc$ Aluminium

Figure 3: Side and top views of the ideal (a) pyrophyllite and (b) talc layers. $\Delta_{\text {Tet. }}$ and $\Delta_{\text {Octa. }}$ are the average thicknesses of the tetrahedral and octahedral sheets, while $\Delta_{\text {Layer }}$ is that of the layer.

correlations of density fluctuations between the electronic clouds and given by: ${ }^{35-37}$

$$
V_{\text {Dispersion }}=-\sum_{i<j}\left[f_{6}^{i j}\left(r_{i j}\right) \frac{C_{6}^{i j}}{\left(r_{i j}\right)^{6}}+f_{8}^{i j}\left(r_{i j}\right) \frac{C_{8}^{i j}}{\left(r_{i j}\right)^{8}}\right]
$$

where $C_{6}^{i j}$ and $C_{8}^{i j}$ are the dipole-dipole and dipole-quadrupole dispersion coefficients and $\mathrm{r}_{i j}$ is the distance between the two atoms $i$ and $j$. The Tang-Toennies damping function $f_{n}^{i j}$ is used to correct the short-range interaction as: ${ }^{38}$

$$
f_{n}^{i j}\left(r_{i j}\right)=1-e^{-b_{n}^{i j} r_{i j}} \sum_{k=0}^{n} \frac{\left(b_{n}^{i j} r_{i j}\right)^{k}}{k !}
$$

where $1 / b_{n}^{i j}$ is the range of the damping. The third term in Eq. 1 corresponds to the short- 
range repulsion, described by a simple exponential form:

$$
V_{\text {Repulsion }}=\sum_{i<j} A^{i j} e^{-B^{i j} r_{i j}}
$$

where $A^{i j}$ and $B^{i j}$ are two parameters. Finally, the last term in Eq. 1 correponds to the polarization, composed of 3 contributions: charge-dipole and dipole-dipole interactions, as well as the energy cost for deforming the electronic cloud of the atom:

$$
\begin{aligned}
V_{\text {Polarization }}= & \sum_{i<j}\left[\frac{q_{i} \mathbf{r}_{i j} \cdot \boldsymbol{\mu}_{j}}{r_{i j}^{3}} g_{4}^{i j}\left(r_{i j}\right)-\frac{\boldsymbol{\mu}_{i} \cdot \mathbf{r}_{i j} q_{j}}{r_{i j}^{3}} g_{4}^{j i}\left(r_{i j}\right)+\frac{\boldsymbol{\mu}_{i} \cdot \boldsymbol{\mu}_{j}}{r_{i j}^{3}}-\frac{3\left(\mathbf{r}_{i j} \cdot \boldsymbol{\mu}_{i}\right)\left(\mathbf{r}_{i j} \cdot \boldsymbol{\mu}_{j}\right)}{r_{i j}^{5}}\right] \\
& +\sum_{i} \frac{\left|\boldsymbol{\mu}_{i}\right|^{2}}{2 \alpha^{i}},
\end{aligned}
$$

where $\alpha^{i}$ is the polarizability of ion $i, \mu^{i}$ and $\mu^{j}$ are the induced dipole, $g^{i j}$ is the short-range correction to the multipolar expansion by the Tang-Toennies damping function (Eq. 7).

$$
g_{4}^{i j}\left(r_{i j}\right)=1-c^{i j} e^{-b_{D}^{i j} r_{i j}} \sum_{k=0}^{4} \frac{\left(b_{D}^{i j} r_{i j}\right)^{k}}{k !} .
$$

The polarization term includes many-body electrostatic effects since the induced dipoles fluctuate along the simulation depending on the positions of all the ions. They are calculated at each molecular dynamics step by minimizing the polarization energy:

$$
\left(\frac{\partial V_{\text {Polarization }}}{\partial \mu_{\alpha}^{i}}\right)=0
$$

In the following, we will not go into the details of the two first terms because the parameters of the charge potential and the dispersion potential are already known. ${ }^{28}$ We will focus on the two other terms, i.e. repulsion and polarization. These contributions to the overall energy depend on ionic properties such as the ionic radius, for the repulsion, or the condensed-phase polarizabilities. The purpose of the present work is therefore to derive the repulsion and the polarization parameters of the PIM force field for the atomic interactions inside clays. We 
now describe the procedure used to determine all the parameters from ab initio calculations.

\section{Parametrization}

\section{DFT calculations}

The optimization procedure aims at finding the set of parameters $\left(\mathrm{A}^{i j}, \mathrm{~B}^{i j}, \mathrm{~b}^{i j}\right.$ and $\left.\mathrm{c}^{i j}\right)$ that minimize the error made in the classical calculation of the forces and dipoles with respect to a series of reference DFT calculations. If this error is sufficiently small, the interaction potential can be considered to be of ab initio accuracy. The optimization procedure is composed of three steps.

We first generate a trajectory by classical molecular dynamics simulation with an available force field (see below). This trajectory is set up to obtain some configurations of the clay system. The configurations must be chosen at the thermodynamic equilibrium and separated in order to be independant to each other. Then, ab initio forces and dipoles are computed on a few configurations using DFT-based electronic structure calculations. The ground-state wavefunction $\left\{\phi^{\circ}\right\}$ of each system is obtained by minimization of the Kohn-Sham energy $\mathrm{E}^{K S}$. The force acting on each atom $\mathbf{F}^{i}$, is calculated using:

$$
\mathbf{F}_{D F T}^{i}=\frac{\delta E^{K S}\left[\left\{\phi^{\circ}\right\}\right]}{\delta \mathbf{r}_{i}}
$$

where $\mathbf{r}_{i}$ is the position of atom $i$. The Kohn-Sham orbitals are delocalized by nature in the plane-wave basis. This renders the assignment of atomic or molecular properties difficult. In contrast, the Maximally Localized Wannier Functions (MLWFs) provide a picture of the electronic density around each atom. They are determined by unitary transformations of the Kohn-Sham eigenvectors and are constructed by choosing the phase so that it minimizes their spread. ${ }^{32}$ A complete theory of electric polarization in crystalline dielectrics has been developed in recent years, ${ }^{42,44,45}$ which validates the calculation of the dipole moments of 
single ions or molecules from the center of charge of the subset of MLWFs which are localized in their vicinity. ${ }^{39-42}$ Figure 4 illutrates the localization of the Wannier centers in a pyrophyllite configuration. We observe that each oxygen atoms can be attributed four Wannier centers while silicium, aluminium and magnesium atoms do not have any of them in their vicinity. This agrees with previous ab initio MD simulation by Vuilleumier et al. ${ }^{43}$

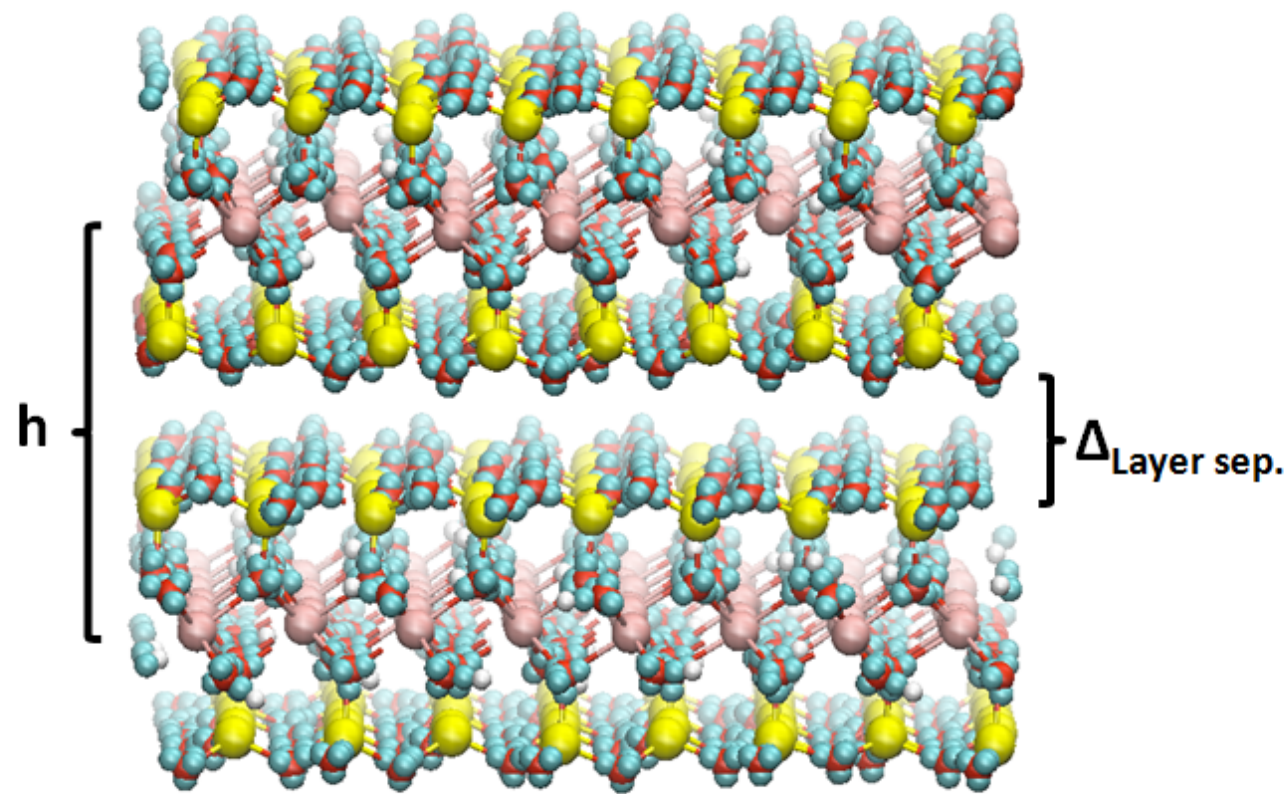

- Oxygen $\bigcirc$ Silicium $\bigcirc$ Hydrogen $\bigcirc$ Aluminium $\bigcirc$ Wanniercenter

Figure 4: Localization of the Wannier centers in a pyrophyllite configuration. $\mathrm{h}$ is the

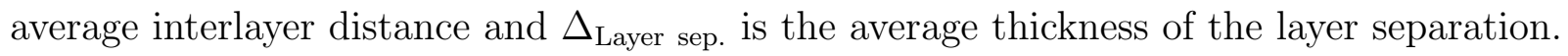

\section{Force- and dipole-matching}

The final step of the optimization procedure consists in determining the parameters $b^{i j}$ and $\mathrm{c}^{i j}$ of the Tang-Toennies function of the polarization term (eq.7) and the parameters $\mathrm{A}^{i j}$ and $\mathrm{B}^{i j}$ of the repulsion term (Eq. 5) that best reproduce the reference DFT forces and dipoles. The polarization parameters are determined numerically by minimizing the error function on the dipoles: 
where $N_{\text {conf }}$ is the number of configurations on which DFT calculations are performed, $N_{\text {atom }}$ is the number of atoms per configuration, $\boldsymbol{\mu}^{\text {classical }}$ and $\boldsymbol{\mu}^{D F T}$ are the dipoles obtained by classical molecular dynamics using a given set of parameters and by DFT, respectively. The repulsion parameters are obtained by minimizing:

$$
\chi_{\text {Forces }}^{2}\left(\mathrm{~A}^{i j}, B^{i j}, b^{i j}, c^{i j}\right)=\frac{1}{\mathrm{~N}_{\text {conf }}} \frac{1}{\mathrm{~N}_{\text {atom }}} \sum_{\text {conf atom }} \sum_{\left\|\mathbf{F}^{\text {classical }}-\mathbf{F}^{\mathrm{DFT}}\right\|^{2}},
$$

where $\boldsymbol{F}^{\text {classical }}$ and $\boldsymbol{F}^{D F T}$ are the forces obtained by classical molecular dynamics and by DFT calculation, respectively.

The optimization procedure ends when the parameters minimizing $\chi_{\text {Dipoles }}^{2}$ and $\chi_{\text {Forces }}^{2}$ are found. The optimization procedure can be summarized as follows:

1. Generation of a series of representative configurations using Classical MD

2. DFT calculations on each of these configurations

(i) Determination of the ground-state wavefunctions, which gives access to the $a b$ initio forces

(ii) Wannier localization, from which the $a b$ initio induced dipoles are calculated

3. Minimization of $\chi_{\text {Dipole }}^{2}$ with respect to the parameters of the polarization term $\left(\mathrm{V}_{\text {Polarization }}\right)$ and the charge transfer parameter $\delta$ within the $\mathrm{OH}$ group, and of $\chi_{\text {Force }}^{2}$ with respect to the repulsion term $\left(\mathrm{V}_{\text {Repulsion }}\right)$.

\section{Simulations Details}

The orthorhombic pyrophyllite simulation box contains two clay layers of lateral dimensions $20.72 \times 26.94 \AA^{2}$, corresponding to 12 unit cells of formula $\mathrm{Si}_{8} \mathrm{Al}_{4} \mathrm{O}_{20}(\mathrm{OH})_{4}$ per 
layer. The monoclinic talc simulation box contains two clay layers of lateral dimensions $15.87 \times 18.36 \AA^{2}$, corresponding to 6 unit cells of formula $\operatorname{Si}_{8} \mathrm{Mg}_{6} \mathrm{O}_{20}(\mathrm{OH})_{4}$ per layer. The interlayer spacing is fixed to $9.192 \AA$ for pyrophyllite ${ }^{33,46}$ and $9.381 \AA$ for talc. ${ }^{34}$ Molecular dynamics simulations are performed in the NVT ensemble with the cp2k simulation package $^{47}$ at $\mathrm{T}=300 \mathrm{~K}$. The first configurations are generated using a PIM with an initial choice of parameters. ${ }^{31}$ During subsequent iterations of the procedure described above, new configurations used for the dipole- and force-matching are generated using a PIM with the current values of these parameters. Periodic boundary conditions are used in the three directions of space. The temperature is controlled via a Nose-Hoover thermostat ${ }^{48,49}$ with a time constant equal to 1 ps. Electrostatic interactions are computed using dipolar Ewald summation, ${ }^{25,50}$ with a tolerance of $10^{-7}$. For each system, we perform an equilibration of 25 ps followed by a 25 ps production run, using a time step of 0.5 fs in the NVT ensemble.

The parametrization of the force field from ab initio simulations is achieved using $\mathrm{N}_{\text {conf }}=$ 3 representative configurations of pyrophyllite and talc obtained from the classical molecular dynamics simulations. Density Functional Theory (DFT) calculations are performed on these configurations with the BLYP ${ }^{51,52}$ and the $\mathrm{PBE}^{53}$ functionals for both systems. GoedeckerTeter-Hutter ${ }^{54-56}$ pseudopotentials are used with the DZVP and the TZV2P plane-wave basis sets ${ }^{57}$ and an energy cutoff of at least 280 Ry. After determining the ground-state wavefunctions, the forces acting on each atom are computed and the dipoles are calculated from the MLWFs. ${ }^{32}$ All ab initio calculations are performed with the cp2k simulation package. ${ }^{47}$ The numerical minimization of forces (Eq. 11) and dipoles (Eq. 10) are performed with the Minuit library. ${ }^{58}$ The final set of parameters depends only slightly on the choice of functional and basis set, as the predicted $a b$ initio dipoles and forces are very similar (see Supplementary Information). 


\section{Force field parameters}

Figure 5 illustrates the comparison between the dipoles and the forces for one of the pyrophyllite configurations calculated with the classical force field and from the DFT calculations.

Table 1: $\chi^{2}$ for the dipoles and the forces for neutral clays

\begin{tabular}{ccc}
\hline \hline Systems & $\chi_{\text {Dipoles }}^{2}$ & $\chi_{\text {Forces }}^{2}$ \\
\hline Pyrophyllite & 0.02981 & 0.25643 \\
Talc & 0.03609 & 0.29764 \\
\hline \hline
\end{tabular}

Table 1 shows the error functions, $\chi_{\text {Dipoles }}^{2}$ and $\chi_{\text {Forces }}^{2}$. The relative error on the dipoles, $\sqrt{\chi_{\text {Dipoles }}^{2}}$, is near $17 \%$ for pyrophyllite and near $19 \%$ for talc. The relative error on the forces, $\sqrt{\chi_{\text {Forces }}^{2}}$, is near $50 \%$ for pyrophyllite and near $54 \%$ for talc. Note that the overall error is dominated by small dipoles and forces. These results can be considered as a good match, i.e. that the dipoles and the forces on all atoms are satisfyingly reproduced by the classical force field. All the parameters are summarized in Table 2 and 3.
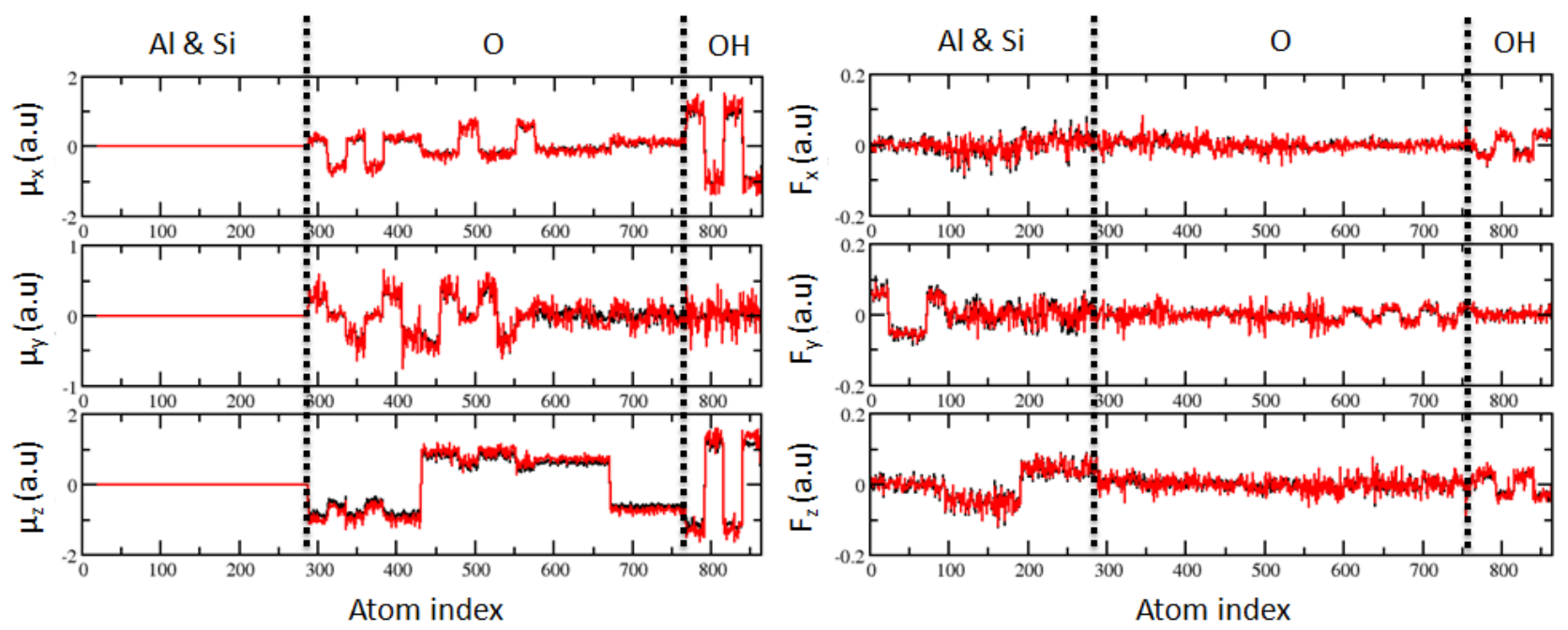

Figure 5: Dipoles (left) and Forces (right) for each atom for one of the pyrophyllite configurations. The predictions of the classical force field (black lines) for the dipole components $\left(\mu_{x}, \mu_{y}\right.$ and $\left.\mu_{z}\right)$ and the force components $\left(F_{x}, F_{y}\right.$ and $\left.F_{z}\right)$ are compared to the DFT results (red lines). 
Table 2: Parameters of the PIM force field for neutral clays. $\delta$ is the transferred charge $(\delta=+0.8983)$. The parameters $\mathrm{C}_{6}^{i j}, \mathrm{C}_{8}^{i j}$ and $\mathrm{b}_{n}^{i j}$ are taken from reference 28 . The bond between the hydrogen and the oxygen atoms of the hydroxyl group is rigid.

\begin{tabular}{ccccccccc}
\hline \hline \multirow{2}{*}{ Systems } & $\begin{array}{c}\text { Ion pair } \\
(\mathrm{ij})\end{array}$ & $\begin{array}{c}\mathrm{A}^{i j} \\
(\mathrm{Ha})\end{array}$ & $\begin{array}{c}\mathrm{B}^{i j} \\
\left(\AA^{-1}\right)\end{array}$ & $\begin{array}{c}\mathrm{C}_{6}^{i j} \\
\left(\mathrm{Ha} \AA^{6}\right)\end{array}$ & $\begin{array}{c}\mathrm{C}_{8}^{i j} \\
\left(\mathrm{Ha}^{8}\right)\end{array}$ & $\begin{array}{c}\mathrm{b}_{n}^{i j} \\
\left(\AA^{-1}\right)\end{array}$ & $\begin{array}{c}\mathrm{c}^{i j} \\
\mathrm{~b}_{D}^{i j} \\
\left(\AA^{-1}\right)\end{array}$ \\
\hline \multirow{5}{*}{ Pyrophyllite } & $\mathrm{O}^{2-}-\mathrm{O}^{2-}$ & 28.375 & 5.486 & 0.974 & 5.247 & 2.718 & 5.385 & 4.999 \\
\multirow{2}{*}{ Tand } & $\mathrm{O}^{2-}-\mathrm{Al}^{3+}$ & 60.001 & 3.326 & 0.048 & 0.156 & 4.168 & 4.330 & 2.133 \\
& $\mathrm{O}^{2-}-\mathrm{Mg}^{2+}$ & 86.277 & 3.661 & 0.048 & 0.156 & 4.168 & 4.471 & 4.996 \\
& $\mathrm{O}^{2-}-\mathrm{Si}^{4+}$ & 29.402 & 2.835 & 0.048 & 0.156 & 4.168 & 5.057 & 3.165 \\
& $\mathrm{O}^{2-}-\mathrm{H}^{(1-\delta)+}$ & 0.000 & 0.000 & 0.000 & 0.000 & 0.000 & 2.002 & 1.861 \\
& $\mathrm{O}_{\mathrm{OH}}^{(2-\delta)-}-\mathrm{O}^{2-}$ & 99.000 & 3.600 & 0.974 & 5.247 & 2.718 & 3.370 & 2.439 \\
& $\mathrm{O}_{\mathrm{OH}}^{(2-\delta)-}-\mathrm{Si}^{4+}$ & 979.802 & 4.825 & 0.048 & 0.156 & 4.168 & 3.849 & 4.269 \\
& $\mathrm{O}_{\mathrm{OH}}^{(2-\delta)-}-\mathrm{Al}^{3+}$ & 20.272 & 3.146 & 0.048 & 0.156 & 4.168 & 3.367 & 1.623 \\
& $\mathrm{O}_{\mathrm{OH}}^{(2-\delta)-}-\mathrm{Mg}^{2+}$ & 35.623 & 3.485 & 0.048 & 0.156 & 4.168 & 3.062 & 1.455 \\
& $\mathrm{O}_{\mathrm{OH}}^{(2-\delta)-}-\mathrm{O}_{\mathrm{OH}}^{(2-\delta)-}$ & 79.477 & 3.300 & 0.974 & 5.247 & 2.718 & 3.229 & 4.9823 \\
& $\mathrm{O}_{\mathrm{OH}}^{(2-\delta)-}-\mathrm{H}^{(1-\delta)+}$ & 0.000 & 0.000 & 0.000 & 0.000 & 0.000 & 2.105 & 0.124 \\
\hline \hline
\end{tabular}

Table 3: Electrostatic parameters of the PIM force field for neutral clays.

\begin{tabular}{ccc}
\hline \hline Ions & $\mathrm{O}^{2-}$ & $\mathrm{OH}^{-}$ \\
\hline$\alpha^{i}\left(\AA^{3}\right)$ & 0.91 & 2.39 \\
\hline \hline
\end{tabular}

\section{Validation}

\section{Systems and simulation details}

Since the present force field is able to correctly reproduce the $a b$ initio dipoles and forces, we now proceed to its validation against experimental data pertaining to the structure and the density of pyrophyllite and talc. We consider three sizes of pyrophyllite and talc simulation cells to assess the possible influence of finite-size effect. Table 4 indicates the different box lengths $\mathrm{A}, \mathrm{B}$ and $\mathrm{C}$ and angles $\alpha_{b o x}, \beta_{b o x}$ and $\gamma_{b o x}$.

The simulation details are the same as above. Each system is first equilibrated in the NVT ensemble during 50 ps. Then, simulations are performed in the anisotropic NPT 
Table 4: Simulated systems for pyrophyllite and talc: A, B and C are the initial box sizes and $\alpha_{b o x}, \beta_{b o x}$ and $\gamma_{b o x}$ the initial box angles.

\begin{tabular}{ccccccccc}
\hline \hline \multirow{2}{*}{ Systems } & $\begin{array}{c}\text { Supercell } \\
\text { dimensions }\end{array}$ & $\begin{array}{c}\mathrm{A} \\
(\AA)\end{array}$ & $\begin{array}{c}\mathrm{B} \\
(\AA)\end{array}$ & $\begin{array}{c}\mathrm{C} \\
(\AA)\end{array}$ & $\begin{array}{c}\alpha_{\text {box }} \\
\left(^{\circ}\right)\end{array}$ & $\begin{array}{c}\beta_{\text {box }} \\
\left(^{\circ}\right)\end{array}$ & $\begin{array}{c}\gamma_{\text {box }} \\
\left({ }^{\circ}\right)\end{array}$ & $\begin{array}{c}\text { Number } \\
\text { of atoms }\end{array}$ \\
\hline \multirow{3}{*}{ Pyrophyllite } & $5 \times 5 \times 2$ & 25.800 & 44.830 & 18.694 & 90.00 & 90.00 & 90.00 & 2000 \\
& $6 \times 6 \times 2$ & 30.960 & 53.796 & 18.694 & 90.00 & 90.00 & 90.00 & 2880 \\
& $7 \times 7 \times 2$ & 36.120 & 62.762 & 18.694 & 90.00 & 90.00 & 90.00 & 3920 \\
\hline \multirow{2}{*}{ Talc } & $5 \times 5 \times 2$ & 26.450 & 45.865 & 18.920 & 90.00 & 99.00 & 90.00 & 2100 \\
& $6 \times 6 \times 2$ & 31.740 & 55.038 & 18.920 & 90.00 & 99.00 & 90.00 & 3024 \\
& $7 \times 7 \times 2$ & 37.030 & 64.211 & 18.920 & 90.00 & 99.00 & 90.00 & 4116 \\
\hline \hline
\end{tabular}

ensemble (all box lengths and angles are allowed to evolve independently) under a pressure of 1 bar during 50 ps of equilibration followed by 150 ps of production. The pressure is controled by an extension of the Nose-Hoover barostat developed by Martyna et al ${ }^{59,60}$ with a barostat time constant equal to 9 ps and the same time constant of 1 ps for the thermostat. Simulations under the same conditions were performed for both our new polarizable force field and the state-of-the-art non-polarizable force field ClayFF. ${ }^{5}$

\section{Lattice parameters}

The unit cell parameters obtained for the equilibrated systems are summarized in Table 5. Since the effect of system size is very limited, we report here averages over all the systems. The results obtained with ClayFF or PIM for the parameters of the elementary unit cell for both clays are in good agreement with the experimental data. In particular, both force fields ensure the integrity of the elementary cell and predict the correct lattice parameters and angles. The simulated densities are also compared to the experimental ones in Table 5. Once again, the overall agreement is good. Such an agreement is already a significant achievement for the present PIM model, which in contrast to ClayFF does not use any experimental input, in particular no information on the experimental structure, during the parametrization process. 
Table 5: Unit cell parameters of pyrophyllite and talc clays. a, b and c are the lattice parameters, $\mathrm{h}$ is the average interlayer distance, $\alpha, \beta$ and $\gamma$ are the angles of the cell and $\rho$ is the density of the system. The relative difference between experimental and simulation results (in percent) is given in parenthesis. The standard errors (SE) are calculated by the error block averaging method. ${ }^{63,64}$ The SE, which apply on the last digit of the given values, are estimated to be 3,8 and 1 for the distances, angles and densities respectively. For example, the 'a' ClayFF parameter of pyrophyllite of 5.216 [3] indicates an SE of 0.003.

\begin{tabular}{|c|c|c|c|c|c|c|c|c|c|}
\hline Systems & Methods & $\mathrm{a}(\AA)$ & $\mathrm{b}(\AA)$ & $\mathrm{c}(\AA)$ & $\mathrm{h}(\AA)$ & $\alpha\left(^{\circ}\right)$ & $\beta\left(^{\circ}\right)$ & $\gamma\left({ }^{\circ}\right)$ & $\rho\left(\mathrm{g} . \mathrm{cm}^{-3}\right)$ \\
\hline \multirow{5}{*}{ Pyrophyllite } & Cl/ & 5.216 & 9.004 & 9.522 & 9.313 & 95.25 & 101.86 & 90.03 & 2.7 \\
\hline & & $(1.1)$ & $(0.4)$ & $(1.9)$ & $(1.3)$ & $(4.5)$ & $(1.4)$ & $(0.4)$ & $(0.0)$ \\
\hline & & 5.241 & 8.951 & 9.550 & 9.389 & 94.94 & 100.08 & 89.88 & 2.7 \\
\hline & & $(1.6)$ & $(0.2)$ & $(2.2)$ & $(2.1)$ & $(4.1)$ & $(0.4)$ & $(0.3)$ & $(0.0)$ \\
\hline & Exp. ${ }^{33,46}$ & 5.160 & 8.966 & 9.347 & 9.192 & 91.18 & 100.46 & 89.64 & 2.7 \\
\hline \multirow{5}{*}{ Talc } & \multirow{2}{*}{ ClayFF } & 5.310 & 9.189 & 9.351 & 9.230 & 92.04 & 95.32 & 90.07 & 2.8 \\
\hline & & $(0.3)$ & $(0.1)$ & $(1.2)$ & $(1.6)$ & $(1.6)$ & $(3.6)$ & $(0.0)$ & $(0.0)$ \\
\hline & \multirow{2}{*}{ PIM } & 5.279 & 9.150 & 9.524 & 9.372 & 90.32 & 98.50 & 89.99 & 2.8 \\
\hline & & $(0.3)$ & $(0.3)$ & $(0.6)$ & $(0.1)$ & $(0.3)$ & $(0.4)$ & $(0.0)$ & $(0.0)$ \\
\hline & Exp. $^{34}$ & 5.293 & 9.179 & 9.469 & 9.381 & 90.57 & 98.91 & 90.03 & 2.8 \\
\hline
\end{tabular}

\section{Sheets structure}

Experimentally, the tetrahedral and the octahedral sheets adjust their lateral dimensions in order to accommodate their lateral misfit. As a result, they deviate from an ideal hexagonal symmetry. Figure 6 illutrates the deformation of the hexagonal cavity. The deformation of the structures can be monitored by following well chosen bond lengths and angles. The simulation results for pyrophyllite and talc are summarized in Table S1 and S2, respectively, obtained by both force fields, together with the available experimental data. Before discussing the microstructure in further detail, one can already note the overall good agreement (within a few percents) between simulations with both force fields and with experiments. As mentioned above, it should be noted that the parametrization of the present PIM model does not rely on experimental information on the microscopic structure. Some discrepancies are observed, which are generally larger with ClayFF (only up to 11-12\% in the worst 
cases $)$. The average thickness of the tetrahedral $\left(\Delta_{\text {Tet. }}\right)$ and octahedral $\left(\Delta_{\text {Octa. }}\right)$ of sheets, of the layer $\left(\Delta_{\text {Layer }}\right)$ and the layer separation $\left(\Delta_{\text {Layer sep. }}\right)$ obtained for the pyrophyllite and talc equilibrated systems are summarized in Table 6 . The results obtained with ClayFF and PIM are both in good agreement with the experimental data.

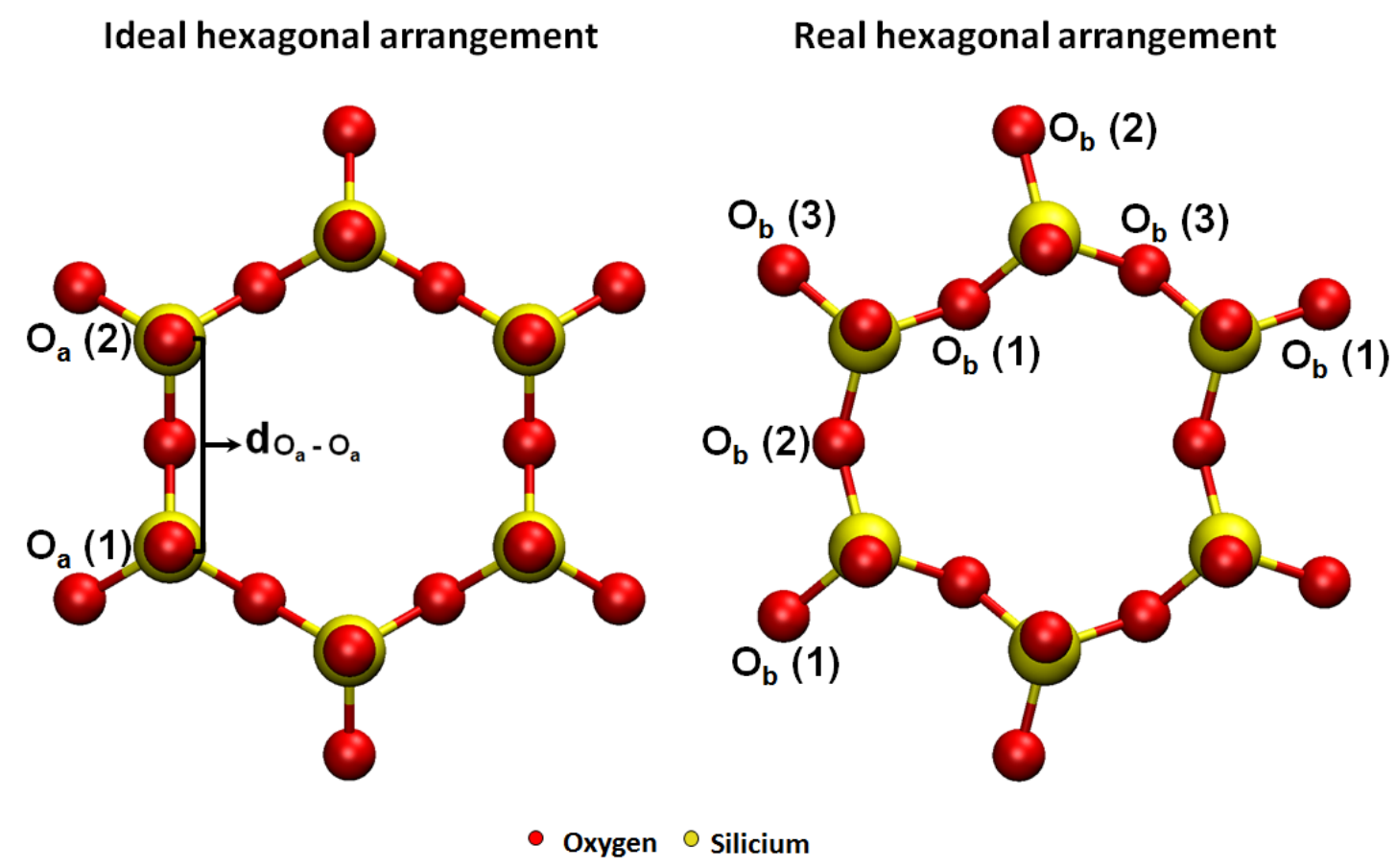

Figure 6: Ideal and real hexagonal silicate ring arrangements

The lateral dimensions of the tetrahedral sheet are usually greater than that of the octahedral one. The distortion of the tetrahedral sheet follows three different mechanisms: ${ }^{33,34,59,61}$ i) tilting of the apical oxygen as evaluated by the angle $\gamma_{\text {tilt }}$ between $\delta_{\mathrm{Si}-\mathrm{O}_{\mathrm{a}}}$ (distance between silicium and apical oxygen atoms) and $\Delta_{\mathrm{Si}-\mathrm{O}_{\mathrm{a}}}$ (distance between silicium and apical oxygen plans) (Figure $7(\mathrm{a})$ ), ii) rotation of the tetrahedron as evaluated by the angle $\alpha_{\text {rot }}$ (i.e., the deviation from $120^{\circ}$ of each angle in the ring (Figure $7(\mathrm{~b}) \&(\mathrm{c})$ ) and iii) increase in the thickness of the tetrahedral sheet as evaluated by the deviation from $109^{\circ} 28^{\prime}$ of the $\mathrm{O}_{\mathrm{a}}-\mathrm{Si}-\mathrm{O}_{\mathrm{b}}$ angle of triads (Figure $7(\mathrm{a})$ ). 
Table 6: Average thickness of the tetrahedral $\Delta_{\text {Tet. }}$ and octahedral $\Delta_{\text {Octa. }}$ sheets, layer $\Delta_{\text {Layer }}$ and layer separation $\Delta_{\text {Layer sep. (see Figures } 3 \text { and } 4 \text { ). The relative difference between }}$ experimental and simulation results (in percent) is given in parenthesis. The standard errors (SE) are calculated by the error block averaging method. ${ }^{63,64}$ The SE, which apply on the last digit of the given values, are estimated to be 7 and 5 for the PIM and ClayFF values respectively.

\begin{tabular}{cccccc}
\hline \hline \multirow{2}{*}{ Systems } & \multirow{2}{*}{ Methods } & $\begin{array}{c}\Delta_{\text {Tet. }} \\
(\AA)\end{array}$ & $\begin{array}{c}\Delta_{\text {Octa. }}(\AA) \\
(\AA)\end{array}$ & $\begin{array}{c}\Delta_{\text {Layer }} \\
(\AA)\end{array}$ & $\begin{array}{c}\Delta_{\text {Layer sep. }}(\AA) \\
\text { Pyrophyllite }\end{array}$ \\
\cline { 2 - 6 } & \multirow{2}{*}{ PIM } & $\begin{array}{c}2.15 \\
(0.1)\end{array}$ & $\begin{array}{c}2.25 \\
(8.1)\end{array}$ & $\begin{array}{c}6.52 \\
(-)\end{array}$ & 2.87 \\
\cline { 2 - 6 } & \multirow{2}{*}{ ClayFF } & 2.04 & 2.29 & 6.46 & 2.86 \\
& \multirow{2}{*}{ Exp. ${ }^{33}$} & 2.15 & 2.08 & - & 2.76 \\
\hline \multirow{5}{*}{ Talc } & \multirow{2}{*}{ PIM } & 2.16 & 2.13 & 6.44 & 2.93 \\
& \multirow{2}{*}{ ClayFF } & $(-)$ & $(-)$ & $(-)$ & $(-)$ \\
\cline { 2 - 6 } & & $(-)$ & $(-)$ & $(-)$ & $(-)$ \\
\cline { 2 - 6 } & \multirow{2}{*}{ Exp. ${ }^{34}$} & - & - & - & - \\
\hline \hline
\end{tabular}

\section{The tilt angle}

The most important distances to consider are the distances between neighbouring apical oxygens $\left(\mathrm{d}_{\mathrm{O}_{\mathrm{a}}-\mathrm{O}_{\mathrm{a}}}\right)$, as illustrated in Figure 6. In fact, a slight extension or shortening of the distance between two apical oxygen atoms will cause the rotation and the tilt of each tetrahedron. Figure 6 illutrates the ideal and the real hexagonal silicate ring arrangements. In an ideal hexagonal silicate ring, $\mathrm{d}_{\mathrm{O}_{\mathrm{a}}-\mathrm{O}_{\mathrm{a}}}=3.05 \AA$. For pyrophyllite, ${ }^{33}$ the mean distance from $\mathrm{O}_{a}(1)$ to $\mathrm{O}_{\mathrm{a}}(2)$ via $\mathrm{O}_{\mathrm{b}}(3)$ and $\mathrm{O}_{\mathrm{a}}(1)$ to $\mathrm{O}_{\mathrm{a}}(2)$ via $\mathrm{O}_{\mathrm{b}}(1)$, where the definition of these atoms can be found in Figure 6, is $2.78 \AA$. The third distance, $\mathrm{O}_{\mathrm{a}}(1)$ to $\mathrm{O}_{\mathrm{a}}(2)$ via $\mathrm{O}_{\mathrm{b}}(2)$, is $3.46 \AA$. For talc, ${ }^{34}$ the shortest and largest distances between two apical oxygens are respectively equal to $3.05 \AA$ and $3.31 \AA$. Table 7 compares the experimental and simulated values. A good agreement is observed for both the ClayFF and PIM force fields.

For both the experimental and the simulation values, the first two distances between 
a

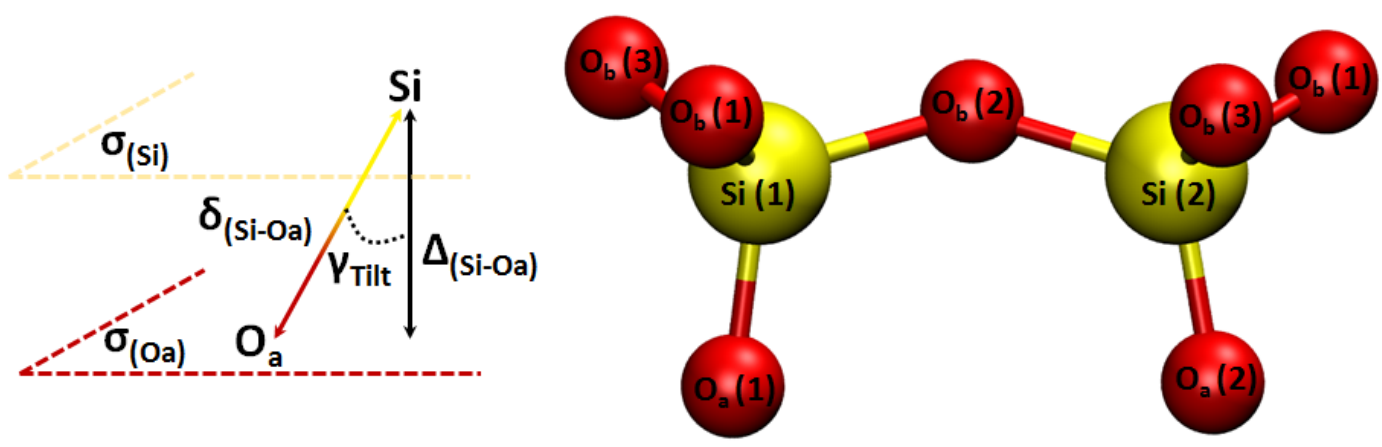

b

C
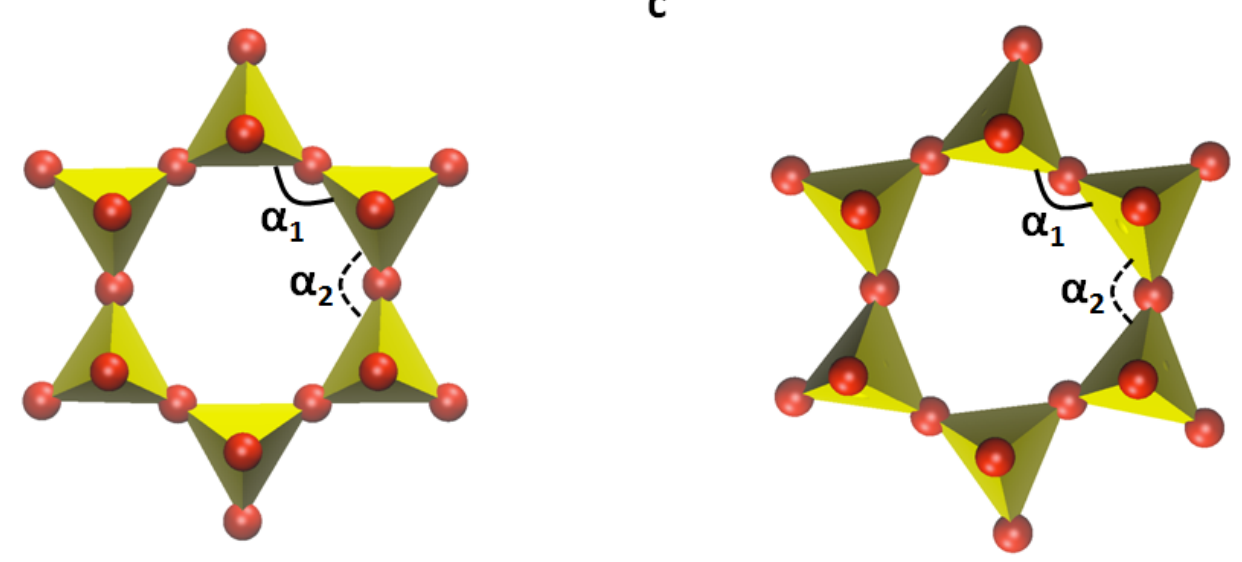

Figure 7: (a) Definition of the tilt angle of tetrahedra, (b) and (c) bottom-up view of the tetrahedral sheet ; $\alpha_{1}=120+2 \times \alpha_{\text {rot }}$ and $\alpha_{2}=120-2 \times \alpha_{\text {rot }}$

Table 7: Separation between apical oxygen atoms. See figure 6 for the definition of the various oxygen atoms. The standard errors (SE) are calculated by the error block averaging method. ${ }^{63,64}$ The SE, which apply on the last digit of the given values, are estimated to be 8 and 7 for the PIM and ClayFF values respectively.

\begin{tabular}{cccc}
\hline \hline \multirow{2}{*}{ Systems } & Methods & $\mathrm{O}_{\mathrm{a}}(1)$ to $\mathrm{O}_{\mathrm{a}}(2)$ via $\mathrm{O}_{\mathrm{b}}(3)(\AA)$ & $\mathrm{O}_{\mathrm{a}}(1)$ to $\mathrm{O}_{\mathrm{a}}(2)$ via $\mathrm{O}_{\mathrm{b}}(2)(\AA)$ \\
& $\mathrm{O}_{\mathrm{a}}(1)$ to $\mathrm{O}_{\mathrm{a}}(2)$ via $\mathrm{O}_{\mathrm{b}}(1)(\AA)$ & 3.29 \\
\hline \hline \multirow{4}{*}{ Pyrophyllite } & ClayFF & 2.93 & 3.45 \\
& PIM & 2.81 & 3.46 \\
\hline \multirow{4}{*}{ Talc } & Exp. & 2.78 & 3.11 \\
& ClayFF & 3.03 & 3.20 \\
& PIM & 2.92 & 3.31 \\
\hline \hline
\end{tabular}


apical oxygens are shorter than the ideal ones, whereas the third distance is longer. This deformation causes a local deformation of the bridge $\mathrm{O}_{\mathrm{a}}(1)-\mathrm{Si}(1)-\mathrm{O}_{\mathrm{b}}(2)-\mathrm{Si}(2)-\mathrm{O}_{\mathrm{a}}(2)$ (Figure $7(\mathrm{a}))$. In turn, the tetrahedra tilt and rotate so that the lateral octahedral and tetrahedral dimensions change. In fact, cations repel each other causing a reconciliation of oxygen atoms common to two octaedra: $\mathrm{O}_{\mathrm{a}}(1)-\mathrm{O}_{\mathrm{a}}(1)^{\mathrm{b}}$ and $\mathrm{O}_{\mathrm{a}}(2)-\mathrm{O}_{\mathrm{a}}(2)^{\mathrm{b}}$ (Figure 1). In contrast with the thickening of the tetrahedral sheet, the thickness of the octahedral one decreases.

For 2:1 layer silicates, the $\mathrm{O}_{\mathrm{a}}-\mathrm{Si}-\mathrm{O}_{\mathrm{b}}(2)$ angle is slightly wider than the $\mathrm{O}_{\mathrm{a}}-\mathrm{Si}-\mathrm{O}_{\mathrm{b}}(1)$ and $\mathrm{O}_{\mathrm{a}}-\mathrm{Si}-\mathrm{O}_{\mathrm{b}}(3)$ angles. The average of the three $\mathrm{O}_{\mathrm{a}}-\mathrm{Si}-\mathrm{O}_{\mathrm{b}}$ angles is a measure of the thickness of the tetrahedron: Tetrahedra are slightly elongated along the $\mathrm{z}$ direction and compressed in the $\mathrm{x}$ and $\mathrm{y}$ directions, thereby producing a $\mathrm{O}_{\mathrm{a}}-\mathrm{Si}-\mathrm{O}_{\mathrm{b}}(2)$ angle larger than the ideal one $\left(109.47^{\circ}\right) .{ }^{33}$ The experimental $\mathrm{O}_{\mathrm{a}}-\mathrm{Si}-\mathrm{O}_{\mathrm{b}}(2)$ angle is equal to $110.5^{\circ}$ for pyrophyllite ${ }^{33}$ and Rayner et al. report a value of $109.2^{\circ}$ for the average $\mathrm{O}_{\mathrm{a}}-\mathrm{Si}-\mathrm{O}_{\mathrm{b}}$ angle. The average simulated $\mathrm{O}_{\mathrm{a}}-\mathrm{Si}-\mathrm{O}_{\mathrm{b}}(2)$ angle is equal to $110.5^{\circ}$ and $110.8^{\circ}$ with the PIM and ClayFF force field, respectively, in good agreement with the experimental result. For talc, we obtain $108.9^{\circ}$ and $109.4^{\circ}$ with the PIM and ClayFF force field, respectively, also in good agreement with the experimental value of $109.2^{\circ}$. As a consequence, the apical oxygen is shifted near the apical oxygens shared by the octahedra edges. This tilt angle $\gamma_{\text {tilt }}$ quantifies the angular deviation of the tetrahedron from the basal plane of apical oxygens (Figure 7(a)). It is given by:

$$
\gamma_{\mathrm{tilt}}=\arccos \frac{\Delta_{\mathrm{Si}-\mathrm{O}_{\mathrm{a}}}}{\delta_{\mathrm{Si}-\mathrm{O}_{\mathrm{a}}}}
$$

where $\Delta_{\mathrm{Si}-\mathrm{O}_{\mathrm{a}}}$ is the mean distance between the planes of silicium atoms and that of the apical oxygen atoms, while $\delta_{\mathrm{Si}-\mathrm{O}_{\mathrm{a}}}$ is the mean distance between silicium and apical oxygens. The experimental tilt angle is equal to $6.0^{\circ}$ for pyrophyllite, ${ }^{33}$ while the PIM and ClayFF force field predict angles of $6.6^{\circ}$ and $4.6^{\circ}$, respectively (see Table 8). Therefore, including manybody effects via the PIM force field seems to improve the description of this tilt compared to ClayFF. We could not find experimental data on the tilt angle for talc. The tilt angle is smaller in the trioctahedral talc case, because of the cation occupancy of all octahedral sites 
that hinders the adjustment of the sheet compared to the dioctahedral pyrophyllite case.

\section{The rotation angle}

The above-mentioned out-of-plane deformations are also associated with in-plane rearrangements, required to adjust the lateral dimensions of the tetrahedral sheet to that of the octahedral one. This results in a rotation of each tetrahedron by an angle $\alpha_{\text {rot }}$. This rotation decreases the symmetry of the tetrahedral sheet and more specifically from a hexagonal to a di-trigonal silicate ring arrangement (see Figure 6). The mean rotation angle is obtained with the formula:

$$
\alpha_{\mathrm{rot}}=\frac{\left|\alpha_{1}-120\right|+\left|\alpha_{2}-120\right|}{4}
$$

where $\alpha_{\text {rot }}$ is the rotation angle, $\alpha_{1}$ and $\alpha_{2}$ are respectively the mean angle of $\mathrm{O}_{\mathrm{b}}(2)-\mathrm{O}_{\mathrm{b}}(3)-$ $\mathrm{O}_{\mathrm{b}}(1)$ and $\mathrm{O}_{\mathrm{b}}(1)-\mathrm{O}_{\mathrm{b}}(2)-\mathrm{O}_{\mathrm{b}}(3)$. The PIM (resp. ClayFF) results for the rotation angle are $11.8^{\circ}$ (resp. $1.1^{\circ}$ ) for pyrophyllite and $4.8^{\circ}$ (resp. $0.9^{\circ}$ ) for talc. Compared to the experimental results, reported with the simulation ones in Table 8, PIM tends to slightly overestimate the rotation angle by 10-40\%, while ClayFF clearly underestimates this distortion of the hexagonal rings, with errors as large as 70-90\%. Overall, the treatment of many-body effects within the polarizable PIM force field gives a better account of the flexibility of the mineral structure. This is all the more important that the structural features discussed here are also present in charged clays and that they have a crucial impact on the local structure. ${ }^{62}$ Moreover, the deformations are known to influence the local properties of the fluid at the surface of the layer, for example the position of the cations or water molecules beside the hexagonal cavities.

\section{Conclusion}

We have successfully developed a polarizable force field for clays. The procedure relies only on ab initio DFT calculations; the repulsion and polarization parameters are extracted from 
Table 8: Average thickness of the silicium-apical oxygen distance $\Delta_{\mathrm{Si}-\mathrm{O}_{\mathrm{a}}}$, angles $\alpha_{1}, \alpha_{2}$, tilt $\gamma_{\text {tilt }}$ and rotation angle of tetrahedra $\alpha_{\text {rot. }}$ (see Figure 7 ). The relative difference between experimental and simulation results (in percent) is given in parenthesis. The standard errors (SE) are calculated by the error block averaging method. ${ }^{63,64}$ The SE, which apply on the last digit of the given values, are estimated to be 8,5, 6 and 3 for the PIM distances, ClayFF distances, PIM angles and ClayFF angles respectively.

\begin{tabular}{|c|c|c|c|c|c|c|}
\hline Systems & Methods & $\begin{array}{c}\Delta_{\mathrm{Si}-\mathrm{O}_{\mathrm{a}}} \\
(\AA)\end{array}$ & $\begin{array}{c}\gamma_{\text {tilt }} \\
\left({ }^{\circ}\right)\end{array}$ & $\begin{array}{l}\alpha_{1} \\
\left(^{\circ}\right)\end{array}$ & $\begin{array}{l}\alpha_{2} \\
\left(^{\circ}\right)\end{array}$ & $\begin{array}{c}\alpha_{\text {rot. }} \\
\left(^{\circ}\right)\end{array}$ \\
\hline \multirow{3}{*}{ Pyrophyllite } & PIM & $\begin{array}{l}1.62 \\
(-) \\
\end{array}$ & $\begin{array}{c}6.6 \\
(9.1) \\
\end{array}$ & $\begin{array}{c}143.5 \\
(-)\end{array}$ & $\begin{array}{l}96.2 \\
(-)\end{array}$ & $\begin{array}{c}11.8 \\
(15.7) \\
\end{array}$ \\
\hline & ClayFF & $\begin{array}{l}1.63 \\
(-)\end{array}$ & $\begin{array}{c}4.6 \\
(23.4)\end{array}$ & $\begin{array}{c}122.7 \\
(-)\end{array}$ & $\begin{array}{c}118.1 \\
(-)\end{array}$ & $\begin{array}{c}1.1 \\
(88.8) \\
\end{array}$ \\
\hline & Exp. ${ }^{33}$ & - & 6.0 & - & - & 10.2 \\
\hline \multirow{3}{*}{ Talc } & PIM & $\begin{array}{l}1.63 \\
(-)\end{array}$ & $\begin{array}{l}3.5 \\
(-)\end{array}$ & $\begin{array}{c}129.5 \\
(-)\end{array}$ & $\begin{array}{c}110.2 \\
(-)\end{array}$ & $\begin{array}{c}4.8 \\
(42.1)\end{array}$ \\
\hline & ClayFF & $\begin{array}{l}1.58 \\
(-)\end{array}$ & $\begin{array}{c}2.9 \\
(-)\end{array}$ & $\begin{array}{c}121.9 \\
(-)\end{array}$ & $\begin{array}{c}118.1 \\
(-)\end{array}$ & $\begin{array}{c}0.9 \\
(73.5)\end{array}$ \\
\hline & Exp. ${ }^{34}$ & - & - & - & - & 3.4 \\
\hline
\end{tabular}

the force- and dipole-optimization procedure. The force field was built and validated for two neutral clays: pyrophyllite and talc. A full structural description of the atomic clay structure is obtained with the new polarizable ion model (PIM) and compared, together with the stateof-the-art non-polarizable force field for clays (ClayFF), to experimental data. The global structure of the unit cell is well reproduced by both force fields. However, introducing the polarization allows for a better description of the microstructure.

The next step in the development of the polarizable force field consists in extending the present approach to the interaction between water molecules, cations $\left(\mathrm{Na}^{+}, \mathrm{Cs}^{+}, \mathrm{Ca}^{2+}\right.$ and $\mathrm{Sr}^{2+}$ ) and charged clays (montmorillonite and hectorite). Such a force field should provide a more accurate description of these complex charged interfacial systems. In turn, this will improve our understanding of the influence of the deformation on the retention and the dynamics of counter-ions and water molecules at the surface of clays and more generally of the interaction of clay minerals with water, including swelling and wettability properties. 


\section{Acknowledgement}

The authors acknowledge the financial support from the Labex MiChem. We also thank the Centre de Calcul Recherche et Enseignement of Jussieu for access to computational resources. We are grateful for the computing resources on OCCIGEN (CINES, French National HPC) obtained through the project x2015097321. 


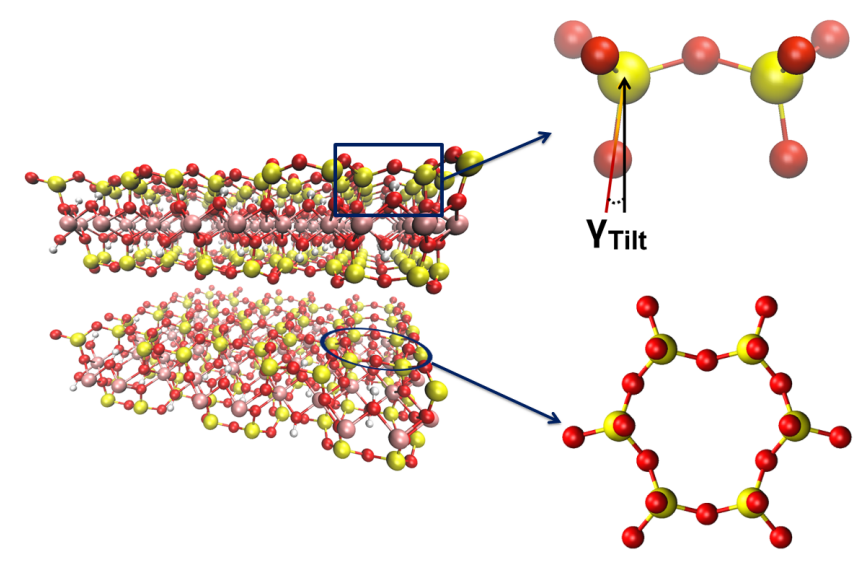




\section{References}

(1) Ricq, M. La classification des minéraux argileux (phyllosilicares). J. Alp. Res. 1965, 53, 708-711.

(2) Wentworth, C. K. A scale of grade and class terms for clastic sediments. J. Geol. 1922, 30, 377-392.

(3) Nickel-Strunz Classification - Primary Groups 10th edition.

(4) Skipper, N.; Retson, K.; McConnell, J. Computer calculation of water-clay interactions using atomic pair potentials. Clay Miner. 1989, 24, 411-25.

(5) Cygan, R.; Liang, J.-J.; Kalinichev, A. Molecular models of hydroxide, oxyhydroxide, and clay phases and the development of a general force field. J. Phys. Chem. B 2004, $108,1255-1266$.

(6) Heinz, H.; Koerner, H.; Anderson, K. L.; Vaia, R. A.; Farmer, B. L. Force field for micatype silicates and dynamics of octadecylammonium chains grafted to montmorillonite. Chem. Mat. 2005, 17, 5658-5669.

(7) Pitman, M. C.; van Duin, A. C. T. Dynamics of confined reactive water in smectite clay-zeolite composites. J. Am. Chem. Soc. 2012, 134, 3042-3053.

(8) Delville, A. Structure and properties of confined liquids: a molecular model of the clay-water interface. J. Phys. Chem. 1993, 97, 9703-9712.

(9) Marry, V.; Turq, P. Microscopic simulations of interlayer structure and dynamics in bihydrated heteroionic montmorillonites. J. Phys. Chem. B 2003, 10\%, 1832-1839.

(10) Wang, J.; Kalinichev, A. G.; Kirkpatrick, R. J. Effects of substrate structure and composition on the structure, dynamics, and energetics of water at mineral surfaces: A molecular dynamics modeling study. Geochim. Cosmochim. Ac. 2006, 70, 562-582. 
(11) Marry, V.; Rotenberg, B.; Turq, P. Structure and dynamics of water at a clay surface from molecular dynamics simulation. Phys. Chem. Chem. Phys. 2008, 10, 4802-4813.

(12) Tambach, T. J.; Bolhuis, P. G.; Hensen, E. J. M.; Smit, B. Hysteresis in clay swelling induced by hydrogen bonding: accurate prediction of swelling states. Langmuir 2006, 22, $1223-1234$.

(13) Botan, A.; Marry, V.; Rotenberg, B.; Turq, P.; Noetinger, B. How electrostatics influences hydrodynamic boundary conditions: poiseuille and electro-osmostic flows in clay nanopores. J. Phys. Chem. C 2013, 117, 978-985.

(14) Rotenberg, B.; Patel, A. J.; Chandler, D. Molecular explanation for why talc surfaces can be both hydrophilic and hydrophobic. J. Am. Chem. Soc. 2011, 133, 20521-20527.

(15) Greathouse, J. A.; Cygan, R. T. Molecular dynamics simulation of uranyl(vi) adsorption equilibria onto an external montmorillonite surface. Phys. Chem. Chem. Phys. 2005, 7, 3580-3586.

(16) Greathouse, J. A.; Cygan, R. T. Water structure and aqueous uranyl(vi) adsorption equilibria onto external surfaces of beidellite, montmorillonite, and pyrophyllite: results from molecular simulations. Environ. Sci. Technol. 2006, 40, 3865-3871.

(17) Kalinichev, A. G.; Wang, J.; Kirkpatrick, R. J. Molecular dynamics modeling of the structure, dynamics and energetics of mineral-water interfaces: application to cement materials. Cem. Concr. Res. 2007, 37, 337-347.

(18) Salanne, M.; Rotenberg, B.; Jahn, S.; Vuilleumier, R.; Simon, C.; Madden, P. A. Including many-body effects in models for ionic liquids. Theor. Chem. Acc. 2012, 131, 1143.

(19) Molina, J. J.; Lectez, S.; Tazi, S.; Salanne, M.; Dufrêche, J.-F.; Roques, J.; Simoni, E.; 
Madden, P. A.; Turq, P. Ions in solutions: determining their polarizabilities from firstprinciples. J. Chem. Phys. 2011, 134, 014511.

(20) Chang, T.-M.; Dang, L. X. Recent advances in molecular simulations of ion solvation at liquid interfaces. Chem. Rev. 2006, 106, 1305-1322.

(21) Skipper, N.; Chang, F.-R.; Sposito, G. Monte Carlo simulation of interlayer molecular structure in swelling clay minerals. I: methodology. Clay Clay Miner. 1995, 43, 285293.

(22) Kamath, G.; Deshmukh, S. A.; Sankaranarayanan, S. K. R. S. Comparison of select polarizable and non-polarizable water models in predicting solvation dynamics of water confined between MgO slabss. J. Phys.: Condens. Matter 2013, 25, 305003.

(23) Marry, V.; Dubois, E.; Malikova, N.; Breu, J.; Haussler, W. Anisotropy of water dynamics in clays: insights from molecular simulations for experimental QENS analysis. J. Phys. Chem. C 2013, 117, 15106-15115.

(24) Madden, P. A.; Wilson, M. 'Covalent'effects in 'ionic' systems. Chem. Soc. Rev. 1996, 25, 339-350.

(25) Aguado, A.; Bernasconi, L.; Jahn, S.; Madden, P. A. Multipoles and interaction potentials in ionic materials from planewave-DFT calculations. Faraday discuss. 2003, 124, $171-184$.

(26) Marrocchelli, D.; Salanne, M.; Madden, P. A.; Simon, C.; Turq, P. The construction of a reliable potential for GeO2 from first principles. Mol. Phys. 2009, 107, 443-452.

(27) Burbano, M.; Marrocchelli, D.; Yildiz, B.; Tuller, H. L.; Norberg, S. T.; Hull, S.; Madden, P. A.; Watson, G. W. A dipole polarizable potential for reduced and doped CeO 2 obtained from first principles. J. Phys.: Condens. Matter 2011, 23, 255402. 
(28) Jahn, S.; Madden, P. A. Modeling earth materials from crustal to lower mantle conditions: a transferable set of interaction potentials for the $\{$ CMAS $\}$ system. Phys. Earth Planet. In. 2007, 162, 129-139.

(29) Tazi, S.; Molina, J. J.; Rotenberg, B.; Turq, P.; Vuilleumier, R.; Salanne, M. A transferable ab initio based force field for aqueous ions. J. Chem. Phys. 2012, 136, 114507.

(30) Molina, J. J.; Dufrêche, J.-F.; Salanne, M.; Bernard, O.; Turq, P. Primitive models of ions in solution from molecular descriptions: a perturbation approach. J. Chem. Phys. 2011, 135, 234509 .

(31) Tazi, S. Description moléculaire des ions aux interfaces argile-eau. Ph.D. thesis, Université Pierre et Marie Curie - Paris 6, Laboratoire Physicochimie des Electrolytes, Colloides et Sciences Analytiques, 2012.

(32) Marzari, N.; Souza, I.; Vanderbilt, D. An introduction to maximally-localized Wannier functions. Psi-K Newsletter 2003, 57, 129-168.

(33) Lee, J. H.; Guggenheim, S. Single crystal X-ray refinement of pyrophyllite-1Tc. Am. Mineral. 1981, 66, 350-357.

(34) Rayner, J. H. The crystal structure of talc. Clay Clay Miner. 1973, 21, 103-114.

(35) Fumi, F. G.; Tosi, M. P. Ionic sizes and born repulsive parameters in the NaCl-type alkali halides - I: the Huggins-Mayer and Pauling forms. J. Phys. Chem. Solids 1964, $25,31-43$.

(36) Tosi, M. P.; Fumi, F. G. Ionic sizes and born repulsive parameters in the NaCl-type alkali halides - II: the generalized Huggins-Mayer form. J. Phys. Chem. Solids 1964, $25,45-52$.

(37) Wang, B.; Truhlar, D. G. Including charge penetration effects in molecular modeling. J. Chem. Theory Comput. 2010, 6, 3330-3342. 
(38) Tang, K. T.; Toennies, J. P. An improved simple model for the van der Waals potential based on universal damping functions for the dispersion coefficients. J. Chem. Phys. 1984, 80, 3726-3741.

(39) Silvestrelli, P. L.; Parrinello, M. Water molecule dipole in the gas and in the liquid phase. Phys. Rev. Lett. 1999, 82, 3308-3311.

(40) Bernasconi, L.; Wilson, M.; Madden, P. A. Cation polarizability from first-principles: Sn2+. Comp. Mater. Sci. 2001, 22, 94-98.

(41) Bernasconi, L.; Madden, P. A.; Wilson, M. Ionic to molecular transition in AlCl 3: an examination of the electronic structure. Phys. Chem. Comm. 2002, 5, 1-11.

(42) Souza, I.; Wilkens, T.; Martin, R. M. Polarization and localization in insulators: generating function approach. Phys. Rev. B 2000, 62, 1666-1683.

(43) Vuilleumier, R.; Sator, N.; Guillot, B. Electronic redistribution around oxygen atoms in silicate melts by ab initio molecular dynamics simulation. J. Non-Cryst. Solids 2011, $357,2555-2561$.

(44) King-Smith, R. D.; Vanderbilt, D. Theory of polarization of crystalline solids. Phys. Rev. B 1993, 47, 1651-1654.

(45) Vanderbilt, D.; King-Smith, R. D. Electric polarization as a bulk quantity and its relation to surface charge. Phys. Rev. B 1993, 48, 4442-4455.

(46) Smyth, J. R.; McCormick, T. C. Crystallographic data for minerals. Miner. Phys. Crystallogr. 1995, 2, 1-17.

(47) CP2K developers group.

(48) Nosé, S. A unified formulation of the constant temperature molecular. J. Chem. Phys. $\mathbf{1 9 8 4 ,} 81,511-519$. 
(49) Nosé, S. A molecular dynamics method for simulations in the canonical ensemble. Mol. phys. 1984, 52, 255-268.

(50) Laino, T.; Hutter, J. Notes on "Ewald summation of electrostatic multipole interactions up to quadrupolar level" [J. Chem. Phys.119, 7471 (2003)]. J. Chem. Phys. 2008, 129, 074102 .

(51) Becke, A. D. Density-functional exchange-energy approximation with correct asymptotic behavior. Phys. Rev. A 1988, 38, 3098-3100.

(52) Lee, C.; Yang, W.; Parr, R. G. Development of the Colle-Salvetti correlation-energy formula into a functional of the electron density. Phys. Rev. B 1988, 37, 785-789.

(53) Perdew, J.; Burke, K.; Ernzerhof, M. Generalized gradient approximation made simple. Phys. Rev. Lett. 1996, 77, 3865-3868.

(54) Goedecker, S.; Teter, M.; Hutter, J. Separable dual-space Gaussian pseudopotentials. Phys. Rev. B 1996, 54, 1703-1710.

(55) Hartwigsen, C.; Goedecker, S.; Hutter, J. Relativistic separable dual-space Gaussian pseudopotentials from H to Rn. Phys. Rev. B 1998, 58, 3641-3662.

(56) Krack, M. Pseudopotentials for H to Kr optimized for gradient-corrected exchangecorrelation functionals. Theor. Chem. Acc. 2005, 114, 145-152.

(57) VandeVondele, J.; Hutter, J. Gaussian basis sets for accurate calculations on molecular systems in gas and condensed phases. J. Chem. Phys. 2007, 127, 114105.

(58) James, F.; Roos, M. Minuit - a system for function minimization and analysis of the parameter errors and correlations. Comput. Phys. Commun. 1975, 10, 343-367.

(59) Martyna, G. J.; Klein, M. L.; Tuckerman, M. Nosé-Hoover chains: the canonical ensemble via continuous dynamics. J. Chem. Phys. 1992, 97, 2635-2643. 
(60) Martyna, G. J.; Tobias, D. J.; Klein, M. L. Constant pressure molecular dynamics algorithms. J. Chem. Phys. 1994, 101, 4177-4189.

(61) Brigatti, M. F.; Galan, E.; Theng, B. K. G. Structures and mineralogy of clay minerals. Dev. Clay Sci. 2006, 1, 19-86.

(62) Tsipursky, S. I.; Drits, V. A. The distribution of octahedral cations in the 2: 1 layers of dioctahedral smectites studied by oblique-texture electron diffraction. Clay Miner. 1984, 19, 177-193.

(63) Frenkel, D.; Smit, D. Understanding molecular simulations: from algorithms to applications, Vol. 1; Academic Press, 2001; pp 98-105.

(64) Flyvbjerg, H.; and Petersen, H. G. Error estimates on averages of correlated data. J. Chem. Phys. 1989, 91, 461-466. 